OPEN ACCESS

Edited by:

Akio Inui,

Kagoshima University, Japan

Reviewed by:

Natasya Trivena Rokot,

Kagoshima University, Japan

Nanami Sameshima Uto,

Kagoshima University, Japan

Akinori Morinaga,

Tokyo Women's Medical University,

Japan

*Correspondence:

Shinichi Suzuk

suzuki_shinichi@phm.kracie.co.jp

Specialty section:

This article was submitted to Clinical Nutrition,

a section of the journal

Frontiers in Nutrition

Received: 06 June 2018

Accepted: 29 January 2019

Published: 19 February 2019

Citation:

Suzuki S, Aihara F, Shibahara M and Sakai K (2019) Safety and Effectiveness of Ninin'yoeito: A Utilization Study in Elderly Patients.

Front. Nutr. 6:14

doi: 10.3389/fnut.2019.00014

\section{Safety and Effectiveness of Ninjin'yoeito: A Utilization Study in Elderly Patients}

\author{
Shinichi Suzuki ${ }^{1 *}$, Fumitaka Aihara ${ }^{2}$, Miho Shibahara $^{2}$ and Katsutaka Sakai ${ }^{3}$ \\ ${ }^{1}$ Pharmaceutical Division, Kracie Pharma Ltd., Tokyo, Japan, ${ }^{2}$ Safety Management Department, Kracie Pharma Ltd., Tokyo, \\ Japan, ${ }^{3}$ Kampo Research Laboratory, Kracie Pharma Ltd., Takaoka, Japan
}

Post-marketing surveillance studies of traditional Japanese medicine in Japan are limited, and currently there are no data for Ninjin'yoeito, which is often used for the elderly because of its efficacy. In this study, we aimed to investigate the post-marketing safety and efficacy of Ninjin'yoeito in elderly patients over 65 years of age in clinical practice in Japan. This survey was an open-label, non-comparative, prospective, multicenter, post-marketing survey conducted at 383 centers between February 2016 and March 2017. In the safety analysis of 808 patients, adverse reactions were reported in 25 patients (3.1\%), most of whom had gastrointestinal disorders (2.1\%). In the efficacy analysis, Ninjin'yoeito was found to significantly improve visual analog scale scores in fatigue/malaise and anorexia at weeks 8, 16, and 24, and weeks 8 and 24 after commencement of treatment, respectively. In addition, the Basic Checklist created by the Ministry of Health, Labor and Welfare of Japan was used as a secondary survey item. The proportion of patients expected to require nursing care significantly decreased after 24 weeks compared with the baseline in four domains (activities of daily living, motor function, oral function, and depression). On the basis of physician assessment, Ninjin'yoeito was rated as "effective" or "moderately effective" in 486 (90.5\%) of 537 cases. As the checklist contains many aspects of frailty, Ninjin'yoeito might be beneficial in preventing frailty. The findings of the present study indicate the safety of Ninjin'yoeito in aged patients, although further integrated clinical trials are necessary to examine its efficacy.

Keywords: ninjin'yoeito, post-marketing surveillance studies, elderly patient, basic checklist, frailty

\section{INTRODUCTION}

Aging is the balance between physiological damage and repair, and the ability to repair physiological damage is assumed to decline with age. The accumulation of physiological damage is presumed to increase the risk of frailty, such as loss of muscle volume, depression, and anorexia in elderly people. In particular, those individuals who have physiological and psychological complications (such as cardiovascular disease, diabetes, hypertension, cancer, and cognitive impairment) are reported to have a high risk of developing frailty-related symptoms.

Ninjin'yoeito (NYT, Ren-Shen-Yang-Rong-Tang in Chinese medicine) is a traditional Japanese medicine (Kampo medicine) that is used for individuals with deteriorated physical or psychiatric conditions, particularly among the elderly. A recent clinical study revealed that NYT has the 
potential to improve cognitive outcome and Alzheimer's diseaserelated depression in Alzheimer's patients (1). In addition, NYT is also reported to improve anorexia and loss of grip strength in elderly individuals $(2,3)$. Furthermore, NYT is reported to improve cancer cachexia in patients with multiple myeloma and fatigue in cancer survivors $(4,5)$. On the basis of these reports, we hypothesized that NYT would be the candidate drug for the treatment of the frailty symptoms observed in elderly individuals. However, to date no post-marketing survey or other relevant studies have been performed to determine the incidence of adverse drug reactions (ADRs) or the efficacy of NYT. Thus, in the present study, we conducted a post-marketing survey in elderly patients to evaluate the safety and effectiveness of NYT.

\section{MATERIALS AND METHODS Study Design and Subjects}

This was an open-label, non-comparative, prospective, multicenter, post-marketing survey to investigate the safety, and efficacy of NYT for self-ambulatory outpatients aged 65 years or older with at least one of the following indications: deterioration in constitution after disease, fatigue/malaise, anorexia, night sweat, coldness of limbs, and anemia. Subjects visited hospitals or clinics at baseline (week 0 ), and thereafter at weeks 8,16 , and 24 . Written informed consent to participate in the study was obtained from each subject or his or her legally authorized representative. The data were collected from February 2016 to March 2017.

\section{Plant Materials and Preparation of the Extract}

NYT, produced by Kracie Pharma Ltd, is composed of the following 12 dried medicinal herbs: Rehmannia root, Japanese Angelica root, Atractylodes rhizome, Poria sclerotium, Ginseng, Cinnamon bark, Peony root, Citrus Unshiu peel, Polygala root, Astragalus root, Schisandra fruit, and Glycyrrhiza (Table 1). Each plant material was identified based on external morphology and authenticated by marker compounds of plant specimens according to the method of the Japanese Pharmacopeia and company's standards.

\section{Survey Item}

Patient characteristics [age, sex, height, body weight, body mass index (BMI), comorbidities, and concomitant medications] and the usage of NYT (indications for use, administration) were evaluated.

\section{Safety}

The occurrence of adverse events (including abnormal laboratory values) during the use of NYT, were evaluated by recording the events, date of onset, severity, outcome (including date of outcome), measures taken, subsequent use of NYT, and a causal relationship with NYT. In addition, adverse events for which drug causality could not be excluded are considered as ADRs in this study. The ADRs were classified on the basis of system organ
TABLE 1 | Medicinal herb composition of Ninjin'yoeito.

\begin{tabular}{lc}
\hline Common name & Weight (g) \\
\hline Rehmannia root & 4 \\
Japanese angelica root & 4 \\
Atractylodes rhizome & 4 \\
Poria sclerotium & 4 \\
Ginseng & 3 \\
Cinnamon bark & 2.5 \\
Peony root & 2 \\
Citrus unshiu peel & 2 \\
Polygala root & 2 \\
Astragalus root & 1.5 \\
Schisandra fruit & 1 \\
Glycyrrhiza & 1 \\
\hline
\end{tabular}

$7.5 \mathrm{~g}$ (clinical daily dose) of this herbal preparation contains $6,700 \mathrm{mg}$ of dried extract obtained from a mixture of above-mentioned crude drugs.

classes (SOC) and preferred terms (PT) of MedDRA/J ver. 20.0. The incidence of ADRs was calculated by the equation as follows:

$$
\begin{aligned}
\text { The incidence }(\%)= & \text { number of patients with SDRs/safety } \\
& \text { population } \times 100
\end{aligned}
$$

\section{Efficacy}

At baseline and each of the subsequent 8-week-interval follow-up visits, the following parameters were assessed: (1) fatigue/malaise and anorexia, using a visual analog scale (VAS), (2) Basic Checklist, (3) severity of the decline in constitution after disease, night sweat, coldness of limbs, and anemia, which were rated by treating physicians on a 4-point scale (3, severe; 2, moderate; 1, mild; and 0, none), (4) body weight, (5) BMI, (6) overall improvement, which was evaluated at the end of the survey by treating physicians on a 4-point scale (3, effective; 2 , moderately effective; 1 , ineffective; and 0 , unevaluable) based on their comprehensive assessment of signs and symptoms noted during the follow-up period.

The Basic Checklist is a questionnaire comprising 25 items (Table 2), which was created by the Ministry of Health, Labor, and Welfare of Japan. It represents a unique screening test used to assess and predict the risk of frailty. According to the criteria, a person with either a total score of $\geq 10$ for questions 1-20 (activities of daily living), $\geq 3$ for questions 610 (motor function), $=2$ for questions 11 and 12 (nutrition), $\geq 2$ for questions 13-15 (oral function), or $\geq 2$ for questions 21-25 (depression) was considered to be in need of care dependency.

\section{Statistical Analysis}

Quantitative data, including age and height, are shown as mean \pm standard deviation (SD) values. The categorical data, including sex, comorbidities, concomitant medications, and drug usage are shown in terms of frequency. VAS and severity scores for each disease were analyzed using a paired $t$-test with Bonferroni adjustment. Body weight and BMI were analyzed using a paired $t$-test. The scores in the five domains of the Basic Checklist 
TABLE 2 | Basic checklist.

\begin{tabular}{|c|c|c|c|}
\hline \multirow{2}{*}{$\begin{array}{l}\text { No } \\
1\end{array}$} & \multirow{2}{*}{$\begin{array}{l}\text { Questions } \\
\text { I usually take the bus or train when going out. }\end{array}$} & \multicolumn{2}{|c|}{ Answer } \\
\hline & & $\square 0$. YES & $\square 1 . \mathrm{NO}$ \\
\hline 2 & I usually buy daily necessities myself. & $\square 0$. YES & $\square 1 . \mathrm{NO}$ \\
\hline 3 & I usually withdraw and deposit money myself. & ๑0. YES & $\square 1 . \mathrm{NO}$ \\
\hline 4 & I sometimes visit my friends. & 口0. YES & $\square 1 . \mathrm{NO}$ \\
\hline 5 & I sometimes turn to my family or friends for advice. & 口0. YES & $\square 1 . \mathrm{NO}$ \\
\hline 6 & I usually climb stairs without using any handrails or wall for support. & $\square 0$. YES & $\square 1 . \mathrm{NO}$ \\
\hline 7 & I usually stand up from a chair without any aids. & $\square 0$. YES & $\square 1 . \mathrm{NO}$ \\
\hline 8 & I usually walk for about 15 min without stopping. & 口0. YES & $\square 1 . \mathrm{NO}$ \\
\hline 9 & I fell in the past year. & 口1. YES & $\square 0 . \mathrm{NO}$ \\
\hline 10 & I am seriously concerned about falling. & 口1. YES & $\square 0 . \mathrm{NO}$ \\
\hline 11 & I have lost $2 \mathrm{~kg}$ or more in the past 6 months. & 口1. YES & $\square 0 . \mathrm{NO}$ \\
\hline 12 & Height: $\mathrm{cm}$, Weight: $\mathrm{kg}$, BMl: $\mathrm{kg} / \mathrm{m}^{2}$. If $\mathrm{BMI}$ is $<18.5$, this item is scored. & $\square 1$. YES & $\square 0 . \mathrm{NO}$ \\
\hline 13 & It is more difficult to eat solid food now compared to 6 months ago. & 口1. YES & $\square 0 . \mathrm{NO}$ \\
\hline 14 & I sometimes choke when drinking something, such as tea or soup. & 口1. YES & $\square 0 . \mathrm{NO}$ \\
\hline 15 & I am often concerned about my dry mouth. & 口1. YES & $\square 0 . \mathrm{NO}$ \\
\hline 16 & I go out at least once a week. & 口0. YES & $\square 1 . \mathrm{NO}$ \\
\hline 17 & I go out less frequently compared to last year. & 口1. YES & $\square 0 . \mathrm{NO}$ \\
\hline 18 & My family or friends point out my memory loss. e.g., "You always ask the same question over and over again." & 口1. YES & $\square 0 . \mathrm{NO}$ \\
\hline 19 & I make a call by looking up phone number. & ๑0. YES & $\square 1 . \mathrm{NO}$ \\
\hline 20 & I sometimes lose track of the date. & 口1. YES & 口0. NO \\
\hline 21 & In the last 2 weeks, I have felt lack of fulfillment in my life. & 口1. YES & $\square 0 . \mathrm{NO}$ \\
\hline 22 & In the last 2 weeks, I have felt a lack of joy when doing the things I used to enjoy. & 口1. YES & $\square 0 . \mathrm{NO}$ \\
\hline 23 & In the last 2 weeks, I have felt difficulty in doing what I could do easily before. & 口1. YES & $\square 0 . \mathrm{NO}$ \\
\hline 24 & In the last 2 weeks, I have felt helpless. & 口1. YES & $\square 0 . \mathrm{NO}$ \\
\hline 25 & In the last 2 weeks, I have felt tired without a reason. & 口1. YES & $\square 0 . \mathrm{NO}$ \\
\hline
\end{tabular}

(activities of daily living, motor function, nutrition, oral function, and depression) were evaluated using the McNemar test. The statistical software "EZR" (Easy R), which is based on R and $\mathrm{R}$ commander (6), was used for statistical analysis. A value of $p<0.05$ was considered statistically significant.

\section{Information on Medical Ethics}

This survey was conducted according to the Ordinance on Standards for Conducting Post-marketing Surveillance and Studies on Drugs (Japanese Ministry of Health, Labor and Welfare Ordinance No. 171, issued on December 20, 2004).

\section{RESULTS}

\section{Patient Disposition}

During the survey period, 954 patients were registered at 383 contracted medical facilities nationwide. From these patients, we collected 910 survey forms. The disposition of the patients is shown in Figure 1. Of the 910 patients surveyed, 808 were included in the population evaluated for safety after excluding 102 patients due to the following factors: violations of entry criteria $(n=43)$, treatment never started $(n=2)$, loss to follow-up after baseline $(n=46)$, and unknown compliance $(n=11)$. Among those individuals in the safety population, 271 patients were excluded due to violations of the exclusion criteria $(n=132)$, poor compliance $(n=16)$, an overall improvement rating of "unevaluable" $(n=88)$, and assessment not being performed as scheduled $(n=35)$, leaving 537 patients in the population used to assess effectiveness.

\section{Patient Characteristics}

The safety analysis assessed 210 males (frequency, 26.0\%) and 598 females $(74.0 \%)$ aged $77.8 \pm 7.4$ years (mean \pm SD), with an average height of $153.5 \pm 8.9 \mathrm{~cm}$. Of the 808 patients, 538 patients (66.6\%) had comorbidities and 262 patients (32.4\%) did not, and 664 patients $(82.2 \%)$ received concomitant medications and 130 patients (16.1\%) did not (Table 3).

The reasons for the use of NYT were fatigue/malaise in 589 cases $(41.1 \%)$, coldness of limbs in 271 cases (18.9\%), anorexia in 253 cases $(17.6 \%)$, deteriorated constitution after disease in 189 cases $(13.2 \%)$, anemia in 72 cases $(5.0 \%)$, and night sweat in 60 cases $(4.2 \%)$. A total of 731 patients $(90.5 \%)$ received the maximum daily dose of $7.5 \mathrm{~g}$, and 616 (76.2\%) and $163(20.2 \%)$ patients followed a twice daily and three times-daily dosing schedule, respectively (Table 4).

\section{Safety}

The incidence of ADRs among the surveyed patients is presented in Table 5A. In the safety analysis $(n=808), 31$ incidents of ADRs occurred in 25 patients, with an incidence of $3.1 \%$. Among these 25 patients, five patients had more than two types of ADRs. The most common ADRs were gastrointestinal disorders occurred in 17 patients $(2.10 \%)$, including five cases of nausea, four of abdominal discomfort, three of diarrhea, and 
two of constipation, and so on. Besides them, three each of metabolism and nutritional disorders, skin and subcutaneous tissue disorders, and general disorders and administration site conditions, together with one each of psychiatric disorders, vascular disorders, and hepatobiliary disorders were recorded in this study (Table 5B).

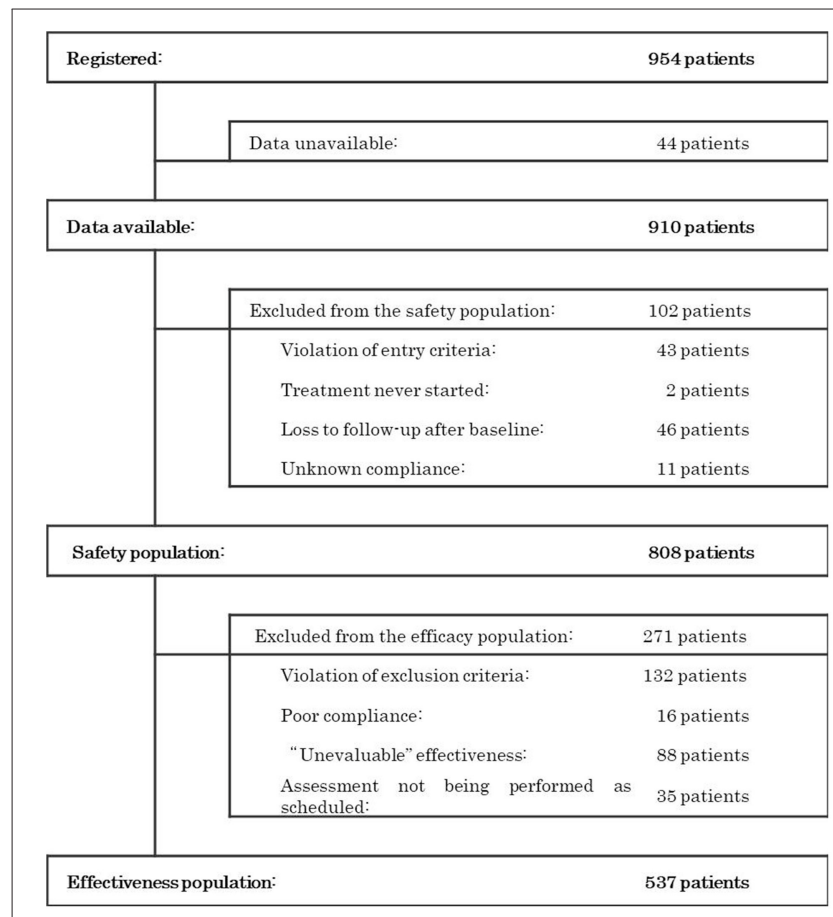

FIGURE 1 | Patient disposition.
The time period before event onset was as follows; $\leq 1$ week in 10 cases; $\leq 2$ weeks in 12 cases; $\leq 1$ month in 17 cases; and $\leq 2$ months in 21 cases (cumulative numbers). The result indicated that approximately $70 \%$ of the reported ADRs occurred within the first 2 months of treatment. In terms of severity, there was one case of cholecystitis leading to hospitalization (with an unknown causal relationship with NYT) and one case of non-mild constipation (with a causal relationship with NYT); the remaining 29 cases were classified as mild. The outcome was reported as "recovered" in 20 cases and "recovering" in eight cases.

\section{Efficacy}

\section{Changes in Symptom Scores on the VAS and Severity Scale}

Compared with baseline scores, NYT significantly improved VAS scores relating to fatigue/malaise and anorexia at weeks 8,16 , and 24, and weeks 8 and 24, respectively (Figure 2). In addition, severity scores for deteriorated constitution after disease, night sweat, coldness of limbs, and anemia significantly improved at weeks 8,16 , and 24 compared with those at baseline (Figure 3). Furthermore, the severity scores for these symptoms were significantly improved at week 24 compared with those at week 8 , and the score for coldness of limbs was significantly improved at week 16 compared with that at week 8 .

\section{Change in Body Weight and BMI}

Body weight and BMI were analyzed in 275 patients whose data at both baseline and week 24 were determined. Mean body weight and BMI increased significantly from $49.4 \pm 9.0 \mathrm{~kg}$ and $20.9 \pm 2.6$ $\mathrm{kg} / \mathrm{m}^{2}$ at baseline to $50.0 \pm 9.0 \mathrm{~kg}$ and $21.2 \pm 2.6 \mathrm{~kg} / \mathrm{m}^{2}$ at week 24 , respectively ( $n=275, p<0.01$ for both). The mean body weight and BMI of males was $58.1 \pm 9.0 \mathrm{~kg}$ and $21.4 \pm 2.7 \mathrm{~kg} / \mathrm{m}^{2}$

TABLE 3 | Patient characteristics.

\begin{tabular}{|c|c|c|c|c|}
\hline & & Total & Male & Female \\
\hline \multicolumn{2}{|c|}{ Safety population } & 808 & $210(26.0 \%)$ & 598 (74.0\%) \\
\hline \multirow[t]{3}{*}{ Age (years) } & Mean \pm SD & $77.8 \pm 7.4$ & $77.5 \pm 8.9$ & $78.0 \pm 7.4$ \\
\hline & Median & 78 & 78 & 78 \\
\hline & Range & $65 \sim 97$ & $65 \sim 96$ & $65 \sim 97$ \\
\hline \multirow[t]{3}{*}{ Height (cm) } & Mean \pm SD & $153.5 \pm 8.9(n=767)$ & $163.7 \pm 6.9(n=200)$ & $150.0 \pm 6.3(n=567)$ \\
\hline & Median & 153.0 & 164.0 & 150.0 \\
\hline & Range & $129 \sim 180$ & $130 \sim 180$ & $129 \sim 166$ \\
\hline \multirow[t]{3}{*}{ Body weight (kg) } & Mean \pm SD & $50.3 \pm 9.9(n=743)$ & $58.1 \pm 11.2(n=196)$ & $47.5 \pm 8.0(n=547)$ \\
\hline & Median & 49.0 & 58.9 & 42.0 \\
\hline & Range & $25 \sim 88$ & $34.9 \sim 88$ & $25 \sim 82$ \\
\hline \multirow[t]{3}{*}{$\mathrm{BMI}\left(\mathrm{kg} / \mathrm{m}^{2}\right)$} & Mean \pm SD & $21.2 \pm 3.2(n=738)$ & $21.6 \pm 3.2(n=195)$ & $21.2 \pm 3.1(n=543)$ \\
\hline & Median & 21.4 & 22.1 & 21.1 \\
\hline & Range & $12.4 \sim 34.0$ & $14.7 \sim 31$ & $12.4 \sim 34.0$ \\
\hline \multirow[t]{3}{*}{ Comorbidities } & Available & $538(66.6 \%)$ & $140(66.7 \%)$ & 398 (66.6\%) \\
\hline & Not available & $262(32.4 \%)$ & 69 (32.9\%) & $193(32.3 \%)$ \\
\hline & Unknown & $8(1.0 \%)$ & $1(0.4 \%)$ & $7(1.1 \%)$ \\
\hline \multirow[t]{3}{*}{ Concomitant medications } & Available & $664(82.2 \%)$ & $161(76.7 \%)$ & 503 (84.1\%) \\
\hline & Not available & $130(16.1 \%)$ & $45(21.4 \%)$ & $85(14.2 \%)$ \\
\hline & Unknown & $14(1.7 \%)$ & $4(1.9 \%)$ & $10(1.7 \%)$ \\
\hline
\end{tabular}


TABLE 4 | Drug usage.

\begin{tabular}{llc}
\hline & & $\boldsymbol{n}(\%)$ \\
\hline Indications for use & Deteriorated constitution after disease & $189(13.2 \%)$ \\
& Fatigue/malaise & $589(41.1 \%)$ \\
& Anorexia & $253(17.6 \%)$ \\
& Night sweats & $60(4.2 \%)$ \\
& Coldness of limbs & $271(18.9 \%)$ \\
Dosage/day & Anemia & $72(5.0 \%)$ \\
& $2.5 \mathrm{~g}$ & $12(1.5 \%)$ \\
& $3.75 \mathrm{~g}$ & $17(2.1 \%)$ \\
& $4 \mathrm{~g}$ & $1(0.1 \%)$ \\
Administration & $5 \mathrm{~g}$ & $46(5.7 \%)$ \\
& $7.5 \mathrm{~g}$ & $731(90.5 \%)$ \\
& $12 \mathrm{~g}$ & $1(0.1 \%)$ \\
& Once-daily & $29(3.6 \%)$ \\
& Twice-daily & $616(76.2 \%)$ \\
& Three times-daily & $163(20.2 \%)$ \\
\hline
\end{tabular}

Indications for use had multiple answers. The total number of responses was 1,434. 0 :frequency.

TABLE 5A | Incidence of adverse drug reactions (ADRs)*.

\begin{tabular}{lc}
\hline & $\boldsymbol{n}$ or $\%$ \\
\hline Safety population (1) & 808 \\
Patients with ADRs (2) & 25 \\
ADR cases & 31 \\
ADR incidence $[(2) /(1) \times 100]$ & $3.1 \%$ \\
\hline
\end{tabular}

*Including the adverse events for which drug causality could not be excluded.

at baseline and $58.4 \pm 9.5 \mathrm{~kg}$ and $21.5 \pm 2.8 \mathrm{~kg} / \mathrm{m}^{2}$ at 24 weeks, respectively ( $n=68$ : no significant difference for both). The mean body weight and BMI of females was $46.5 \pm 6.9 \mathrm{~kg}$ and $20.7 \pm 2.5$ $\mathrm{kg} / \mathrm{m}^{2}$ at baseline and $47.2 \pm 6.8 \mathrm{~kg}$ and $21.0 \pm 2.5 \mathrm{~kg} / \mathrm{m}^{2}$ at 24 weeks, respectively ( $n=207, p<0.01$ for both).

\section{Change in the Scores Assessed Using the Basic Checklist}

Figure 4 shows the percentages of patients who met the cutoff criteria for the five domains (activities of daily living, motor function, nutrition, oral function, and depression) at baseline and week 24. The percentage of patients who were considered to be in need of care dependency decreased significantly at week 24 in terms of activities of daily living (questions 1-20, Figure 4A), motor function (questions 6-10, Figure 4B), oral function (questions 13-15, Figure 4D), and depression (questions 2125 , Figure 4E). The changes observed in the nutrition domain (questions 11 and 12, Figure 4C) were not significant.

\section{Overall Improvement}

In the effectiveness analysis $(n=537)$, treatment was rated as "effective" in 219 patients (40.8\%), "moderately effective" in 267 patients (49.7\%), and "ineffective" in 51 (9.5\%) patients (Figure 5).
TABLE 5B | Incidence of individual type of adverse drug reactions (ADRs).

\begin{tabular}{|c|c|c|c|}
\hline SOC & $n(\%)$ & PT & $N(\%)$ \\
\hline \multirow{2}{*}{$\begin{array}{l}\text { Metabolism and } \\
\text { nutrition disorders }\end{array}$} & $3(0.37 \%)$ & Decreased appetite & $2(0.25 \%)$ \\
\hline & & Hypokalaemia & $1(0.12 \%)$ \\
\hline Psychiatric disorders & $1(0.12 \%)$ & Anxiety & $1(0.12 \%)$ \\
\hline Vascular disorders & $1(0.12 \%)$ & Hypertension & $1(0.12 \%)$ \\
\hline \multirow[t]{9}{*}{$\begin{array}{l}\text { Gastrointestinal } \\
\text { disorders }\end{array}$} & $\begin{array}{c}17 \\
(2.10 \%)^{\star}\end{array}$ & Nausea & $5(0.62 \%)$ \\
\hline & & Abdominal discomfort & $4(0.50 \%)$ \\
\hline & & Diarrhea & $3(0.37 \%)$ \\
\hline & & Constipation & $2(0.25 \%)$ \\
\hline & & Eructation & $1(0.12 \%)$ \\
\hline & & Abdominal pain upper & $1(0.12 \%)$ \\
\hline & & Feces discolored & $1(0.12 \%)$ \\
\hline & & Vomiting & $1(0.12 \%)$ \\
\hline & & Others & $1(0.12 \%)$ \\
\hline Hepatobiliary disorders & $1(0.12 \%)$ & Cholecystitis $^{\star \star}$ & $1(0.12 \%)$ \\
\hline \multirow{3}{*}{$\begin{array}{l}\text { Skin and subcutaneous } \\
\text { tissue disorders }\end{array}$} & $3(0.37 \%)$ & Pruritus & $1(0.12 \%)$ \\
\hline & & Eczema & $1(0.12 \%)$ \\
\hline & & Rash & $1(0.12 \%)$ \\
\hline \multirow{3}{*}{$\begin{array}{l}\text { General disorders and } \\
\text { administration site } \\
\text { conditions }\end{array}$} & $3(0.37 \%)$ & Chest discomfort & $1(0.12 \%)$ \\
\hline & & Malaise & $1(0.12 \%)$ \\
\hline & & Oedema & $1(0.12 \%)$ \\
\hline
\end{tabular}

The ADRs were classified on the basis of system organ class (SOC) and preferred terms (PT) of MedDRAVJ ver. 20.0. n, number of patients; $N$, number of cases; (), the incidence was calculated by the equation, the rate $(\%)=$ number of patients/safety population $\times$ 100.

*Among 17 patients, two patients have two types of ADRs.

${ }^{\star \star}$ Causation was not established.

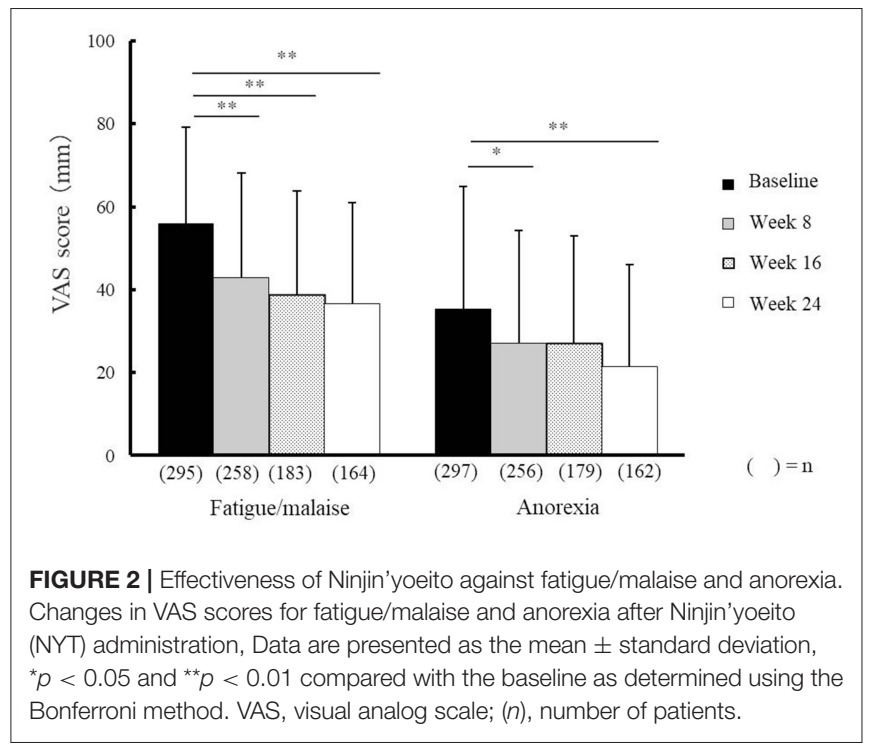

\section{DISCUSSION}

At present there is no post-marketing survey available for NYT, and the present study is the first post-marketing 


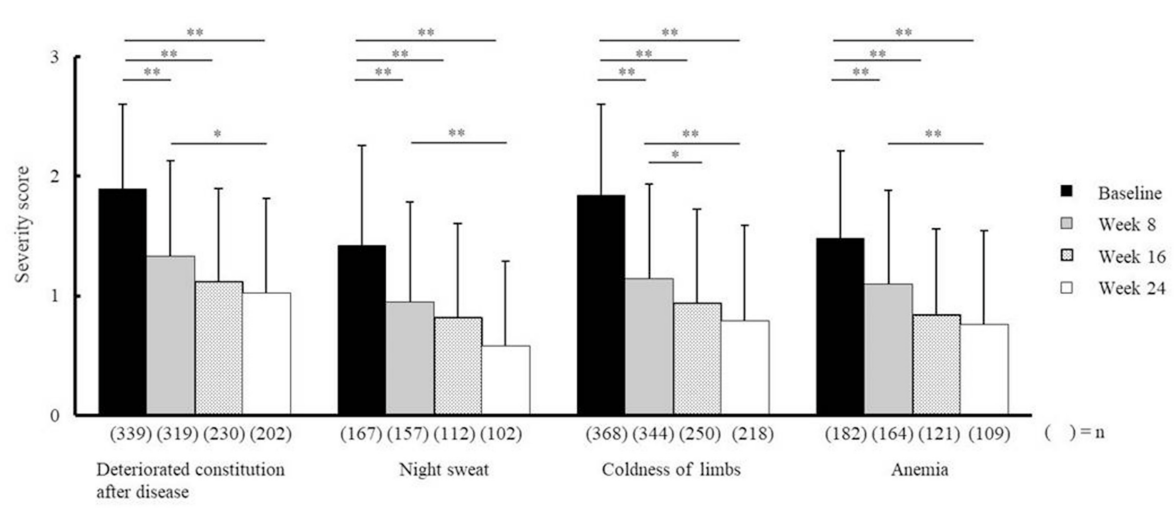

FIGURE 3 | Effectiveness of Ninjin'yoeito according to physician assessment. Changes in severity scores for deteriorated constitution after disease, night sweat, coldness of limbs, and anemia after Ninjin'yoeito (NYT) administration, Data are presented as the mean \pm standard deviation, ${ }^{*} p<0.05$ and ${ }^{* *} p<0.01$ compared with the baseline as determined using the Bonferroni Method. (n), number of patients.
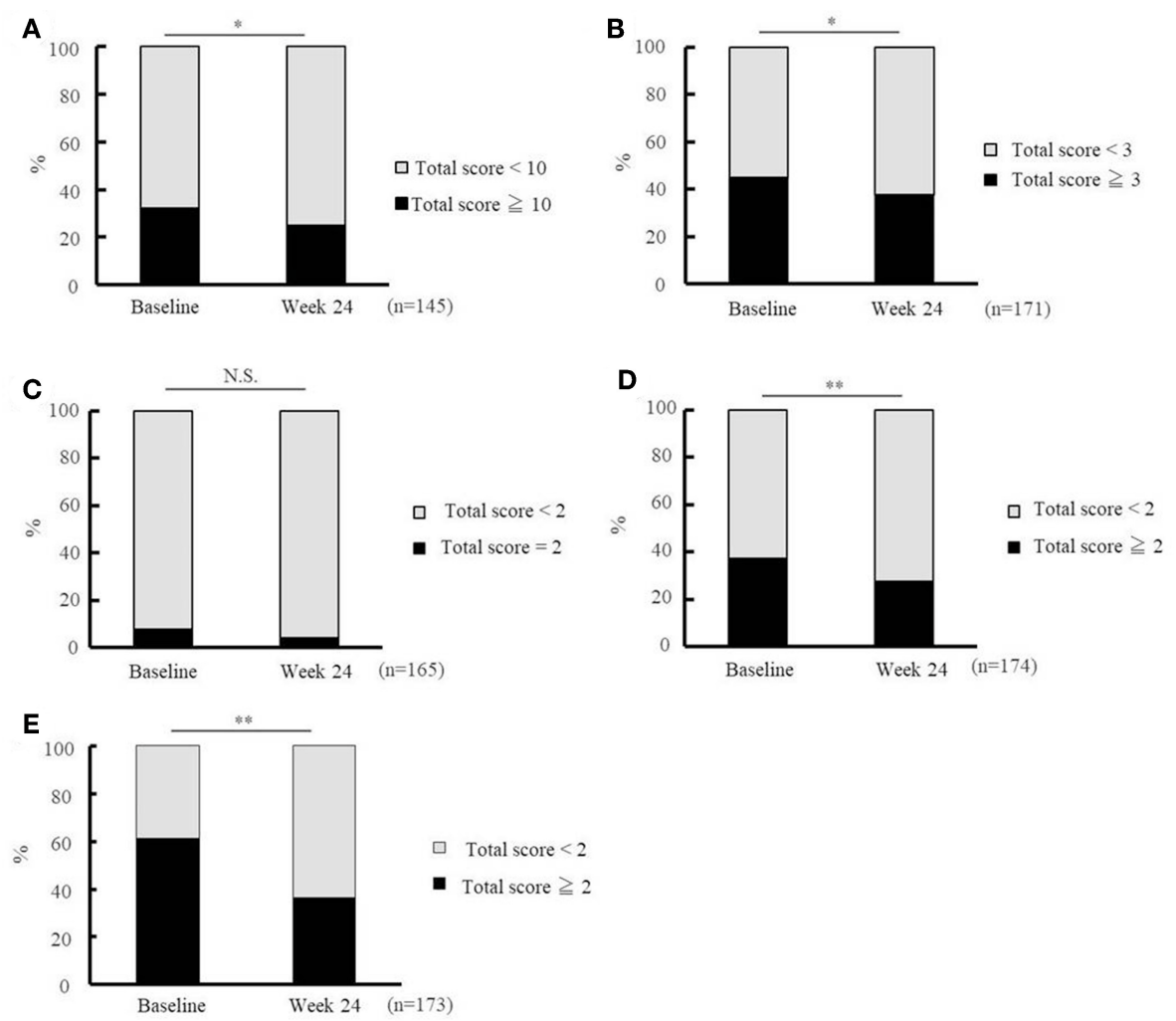

FIGURE 4 | Effectiveness of Ninjin'yoeito as determined by Basic Checklist assessment. Changes in the risk ratio of care dependency accessed using the Basic Checklist after Ninjin'yoeito (NYT) administration: questions 1-20 for activities of daily living assessment (A), questions 6-10 for motor function assessment (B), questions 11 and 12 for nutritional assessment (C), questions 13-15 for oral function assessment (D), and questions 21-25 for depression assessment (E). Data are presented as the mean \pm standard deviation, ${ }^{*} p<0.05$ and ${ }^{* *} p<0.01$ compared with the baseline as determined using the McNemar test. According to the criteria, a person with a total score of $\geq 10$ for questions $1-20$ (activities of daily living), $\geq 3$ for questions $6-10$ (motor function), = 2 for questions 11 and 12 (nutrition), $\geq 2$ for questions 13-15 (oral function), or $\geq 2$ for questions 21-25 (depression) was considered to be in need of care dependency; Basic Checklist, the 25-item Basic Checklist; (n), number of patients.

reports for NYT. We found that the incidence of ADRs was $3.1 \%$ (Table $\mathbf{5 A}$ ) and the major adverse reactions were gastrointestinal disorders (2.1\%; Table 5B). Approximately
$70 \%$ of ADRs in the cumulative incidence of adverse reactions occurred within 2 months after the administration of NYT. 


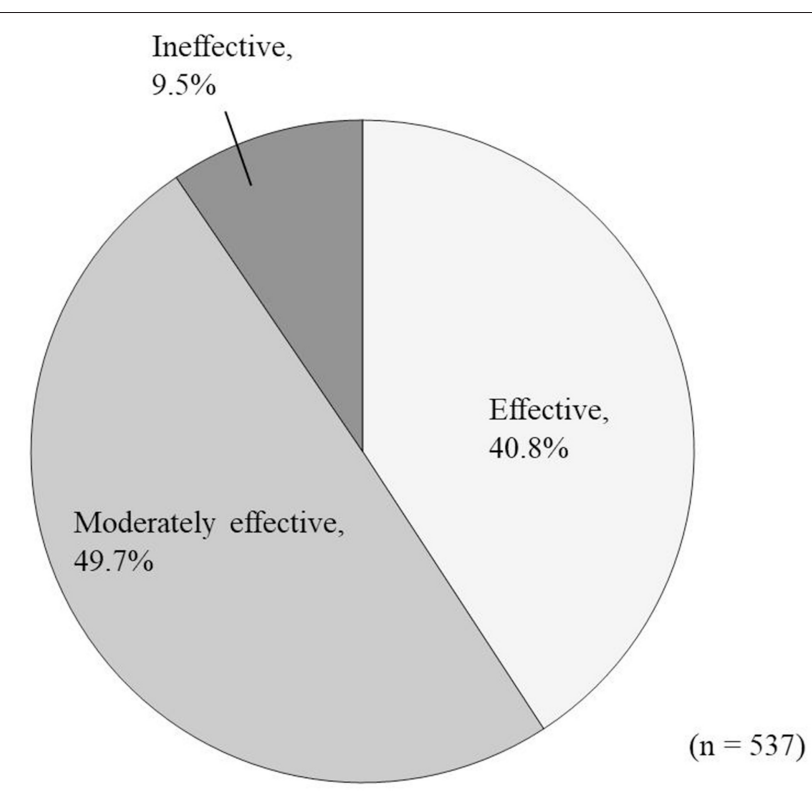

FIGURE 5 | Overall improvement in response to Ninjin'yoeito administration according to physician assessment.

VAS scores indicated that fatigue/malaise and anorexia scores improved after administration of NYT (Figure 2). According to the judgments of the physicians in charge, the severity scores were significantly improved in each of the following items: the deteriorated constitution after disease, night sweat, coldness of limbs, and anemia (Figure 3). Furthermore, we found that NYT increased BMI at week 24 especially in female patients. Interestingly, previous study suggested that mortality was related with the BMI score in older women with frailty (7). A recent report has indicated that NYT strengthened grip power in a comparative open-label trial in patients aged 65 and older (3). Moreover, anorexia and apathy improved following NYT administration in patients with dementia (8). These findings and those of the present trial indicate the beneficial effects of NYT in elderly people.

The Basic Checklist, a screening tool used to detect subjects in need of nursing care dependency, has many frailty-related aspects (9), as frailty is known to be closely related to the need of future care dependency. The satisfactory validity of the Basic Checklist has previously been verified by Kamegaya et al. (10),

\section{REFERENCES}

1. Kudoh C, Arita R, Honda M, Kishi T, Komatsu Y, Asou H, et al. Effect of ninjin'yoeito, a Kampo (traditional Japanese) medicine, on cognitive impairment and depression in patients with Alzheimer's disease: 2 years of observation. Psychogeriatr Off J Jpn Psychogeriatr Soc. (2016) 16:85-92. doi: $10.1111 /$ psyg. 12125

2. Sakisaka N, Mitani K, Sempuku S, Imai T, Takemoto Y, Shimomura H, et al. A clinical study of ninjin'yoeito with regard to frailty. Front Nutr. (2018) 5:73. doi: 10.3389/fnut.2018.00073 who followed 21,325 functionally independent elderly people for 3 years, and found that the subjects with more negative answers to Basic Checklist questions, particularly questions 1-20, had higher odds ratios for care dependency. In the present study, NYT improved the index of 1-20 in the Basic Checklist (Figure 4). These results indicate that NYT might have the potential to decrease the need for care dependency.

Questions 21-25 of the Basic Checklist are used for the detection of depression. In the present study, ratings were improved for all of these five questions, suggesting that NYT might reduce the risk of psychiatric/psychological frailty. According to a previous study (1), the depression ratings of Alzheimer's patients receiving both donepezil and NYT treatment, were significantly improved after 2 years treatment, by comparing with those receiving donepezil alone. In this context, the results of Kudoh et al. support our current findings.

As shown in this trial, NYT improved many Basic Checklist items, and it is thus possible that NYT not only prevents physical frailty but also psychiatric/psychological frailty.

Our study has some limitations, the most important of which is that there was no control group. Accordingly, further trials on the safety and efficacy of NYT are highly desirable.

\section{CONCLUSIONS}

The findings of the present post-marketing survey for NYT indicate that the administration of this drug does not cause serious ADRs and might improve not only physical but also psychiatric/psychological frailty in elderly people. Further trials that include control groups are warranted.

\section{AUTHOR CONTRIBUTIONS}

All authors assisted in designing the study. SS wrote the initial draft of the manuscript. KS contributed to data analysis and interpretation, and assisted in the preparation of the manuscript. FA and MS contributed to data collection and interpretation, and critically reviewed the manuscript. All authors approved the final version of the manuscript, and agree to be accountable for all aspects of the work.

\section{FUNDING}

The essential part of this article was published in Japanese in 医学と薬学 (Igaku to yakugaku) 74(10)1285-1297, 2017. 
6. Kanda Y. Investigation of the freely available easy-to-use software "EZR" for medical statistics. Bone Marrow Transpl. (2013) 48:452-458. doi: 10.1038/bmt.2012.244

7. Boutin E, Natella P-A, Schott A-M, Bastuji-Garin S, David J-P, Paillaud $\mathrm{E}$, et al. Interrelations between body mass index, frailty, and clinical adverse events in older community-dwelling women: the EPIDOS cohort study. Clin Nutr Edinb Scotl. (2018) 37:1638-1644. doi: 10.1016/j.clnu.2017. 07.023

8. Ohsawa M, Tanaka Y, Ehara Y, Makita S, Onaka K. A possibility of simultaneous treatment with the multicomponent drug, Ninjin'yoeito, for anorexia, apathy, and cognitive dysfunction in frail Alzheimer's Disease Patients: an open-label pilot study. J Alzheimers Dis Rep. (2017) 1:229-35. doi: $10.3233 /$ ADR-170026

9. Arai H. Implication of Frailty in elderly people. Jpn J Geriatr. (2014) 51:497501. doi: 10.1016/j.jacep.2016.04.013
10. Kamegaya T, Yamaguchi H, Hayashi K. Evaluation by the basic checklist and the risk of 3 years incident long-term care insurance certification. J Gen Fam Med. (2017) 18:230-6. doi: 10.1002/jgf2.52

Conflict of Interest Statement: The authors declare that the research was conducted in the absence of any commercial or financial relationships that could be construed as a potential conflict of interest.

Copyright (C) 2019 Suzuki, Aihara, Shibahara and Sakai. This is an open-access article distributed under the terms of the Creative Commons Attribution License (CC BY). The use, distribution or reproduction in other forums is permitted, provided the original author(s) and the copyright owner(s) are credited and that the original publication in this journal is cited, in accordance with accepted academic practice. No use, distribution or reproduction is permitted which does not comply with these terms. 